\title{
Synthesis Some of New Substituted 1,3,4-Thiadiazole and 1,2,4-Triazole
}

\author{
Tamara T. Alsafar'; Amal N. Ali ${ }^{2 *}$ \\ ${ }^{1,2}$ Department of Chemistry, College of Education for Pure Science, University of Mosul, Iraq.
}

Email: ${ }^{1}$ tamara.alsafar@gmail.com, ${ }^{2 *}$ dr.amal.nafeali@yahoo.com

(Received July 20, 2019; Accepted October 24, 2019; Available online March 01, 2020)

DOI: 10.33899/edusj.2019.125949.1008, @ 2020, College of Education for Pure Science, University of Mosul.

This is an open access article under the CC BY 4.0 license (http://creativecommons.org/licenses/by/4.0/).

\begin{abstract}
:
The aim of this paper, the synthesis of new series of substituted 1,3,4-thaidiazole and 1,2,4triazol from reaction of the carboxylic acid (2-naphthoic acid,4-methyl benzoic acid) with absolute ethanol in the presence of concentrated sulfuric acid to give esters. the above synthesis ester were converted to acid hydrazide by their reaction with hydrazine hydrate in ethanol, which then reacted with ammonium thiocyanate and hydrochloric acid in ethanol or with phenylisothiocyanate in absolute ethanol to give substituted thiosemicarbazides compounds. the substituted thiosemicarbazides then uses to synthesis of many hyterocyclic compounds like substituted 1,3,4-thiadiazole and 1,2,4-triazole by its reaction with concentrated sulfuric acid and sodium hydroxide respectively. the substituted thiosemicarbazides then cyclization to substituted 3,4-diamine-1,2,4-triazole when treated with hydrazine hydrate. And finally the N- acetyl-N-substituted hydrazide compounds synthesis by treated hydrazide with acetyl chloride in anhydrous tetrahydrofuran which then cyclized to 2-methyl substituted-1,2,4-thiadiazole by their reaction with diphosphorus pentoxide in xylene. The structure of the synthesized compounds were confirmed By physcical \& spectroscopic techniques infrared (IR) and $\left({ }^{1} \mathrm{H}-\mathrm{NMR}\right)$ data.
\end{abstract}

Keyword: Hyterocyclic, thiadiazole, triazole, thiosemicarbazide

$$
\begin{aligned}
& \text { تحضير عدد من المعوضات 4,3,1- ثايادايازول و 4,2,1- ترايازول الجديدة } \\
& \text { 1"تماره طلال الصفا و 2"(مل نافع علي } \\
& \text { 2,1 قسم الكيمياء/ كلية التربية للعلوم الصرفة/ جامعة الموصل/ الموصل/ العراق }
\end{aligned}
$$

تهدف هذه الدراسـة الى تحضسير سلسلة جديدة من معوضـات 4,3,1- ثايادايازول و 4,2,1- ترايازول من مفاعلة الحوامض

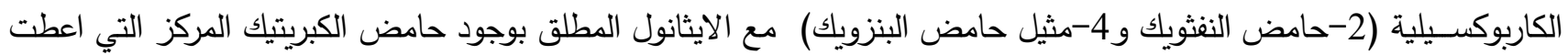

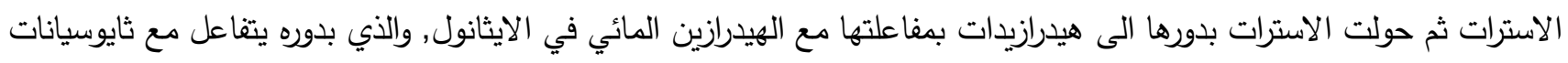

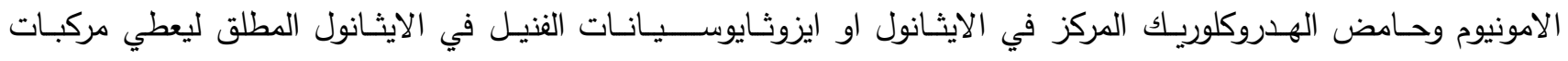

الثايوسيميكاربازيدات المعوضة. والتي تم استعمالها في تحضير العديد من المركبات الحقية غير المتجانسة منها معوضات 4,3,1- 


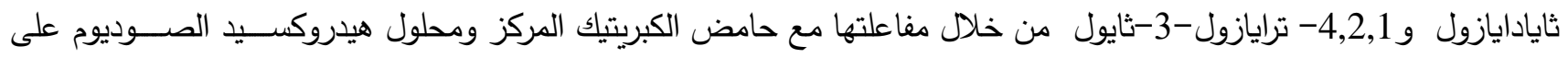

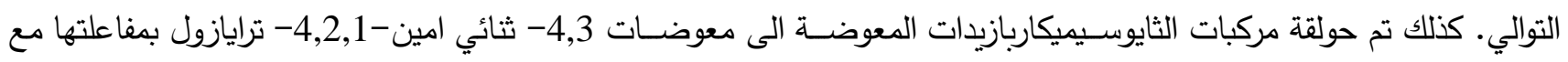
الهيدرازين المائي, واخيرا تم تحضـير مركبات N-N اسيتيل -N-N معوض هيدرازيد عن طريق مفاعلة الهيدرازيد مع كلوريد الاسـيتيل ورباعي هيدروفيوران الجاف والذي تم حولقتها الى 2- مثيل -4,3,1- ثايادايازول المعوض بمفاعلته مع خماســــي كبريتيد ثنائي

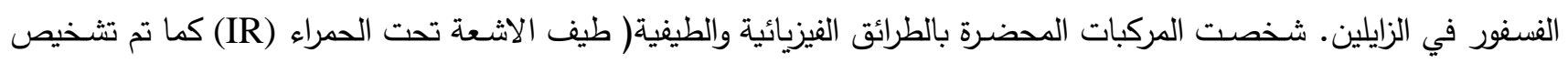
بعض المركبات بواسطة طيف الرنين النووي المغناطيسي(1'H-NMR الكلمات المفتاحية: غيرالمتجانسة, ثايادايازول, ترايازول, ثايوسيميكاربازيد

\section{Introduction المقدمة}

تعد معوضـات 4,3,1- ثايادايازول ومعوضـات 4,2,1-ترايازول ذات أهمية واضـــة في المجالين الصـناعي والصـيدلاني

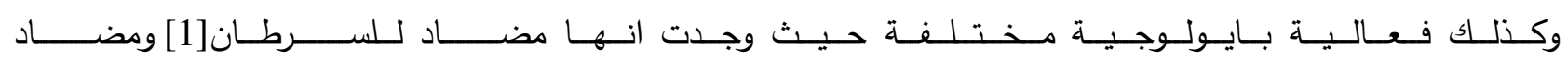
للاكتئاب [2] ومضاد للميكروبات[3] , مماشجع الباحثين على دراستها والأهتمام بتحضيرها. أن أفضل الطرق وأكثرها شيوعا لتحضير معوضـات 4,3,1- ثايادايازول هي عن طريق فقدان معوضـات الثايوسيميكاربازيد

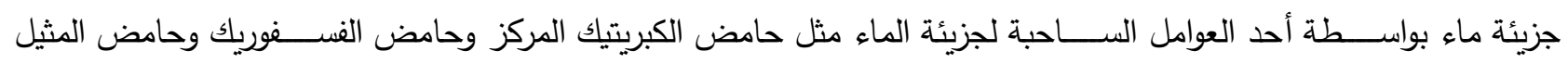
سلفونيك[4].

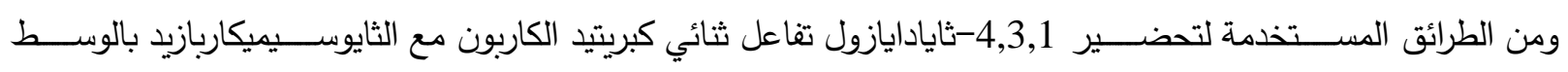
القاعدي[5].

وقام الباحث Radwan [6] وآخرون عام 2017 بتحضير حلقة 4,3,1- ثايادايازول من إضافة حامض الكبريتيك المركز إلى مركبات الثايوسيميكاربازيد المقابلة عند درجة الصفر المئوي مع تحريك المزيج لمدة 3 ساعات عند درجة حرارة الغرفة لتعطي 5

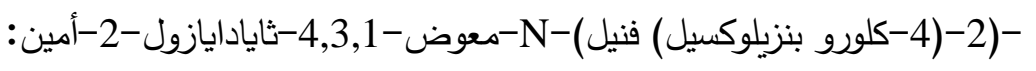<smiles>[R]Nc1nnc(-c2ccccc2OCc2ccc(Cl)cc2)s1</smiles>

$\mathrm{R}=$ phenyl,Allyl, m-Tolyl, p-Tollyl, o-Tollyl

ومن الطرق المهمة في تحضير حلقة الترايازول طريقة حولقة الثايوسيميكاربازيد المعوض باستخدام هيدروكسيد الصوديوم أو الهيدرازين المائي[7].

وحضرت حلقة الترايازول من الهيدرازيد بمفاعلته مع ثنائي كبريتيد الكاربون لتحضير ملح البوتاسيوم ثايوسيميكاربازيد ثم حولقة الملح باستخدام الهيدرازين المائي[8]. وفي عام 2016 تمكن الباحث Paruch [9] وآخرون من تحضير مشتقات جديدة 4,2,1-ترايازول بخطوتين الخطوة الأولى لفي تحضيرالهيدرازيد-3هيدروكسي حامض النفويك وثم تكثيفها مع ايزوثايوسيانات لتعطي 4,1- ثنائي معوض مشتقات الثايوسيميكاربازيد ومن ثم حولقتها إلى مشتقات جديدة من 4,2,1- ترايازول باستخدام محيط قاعدي: 


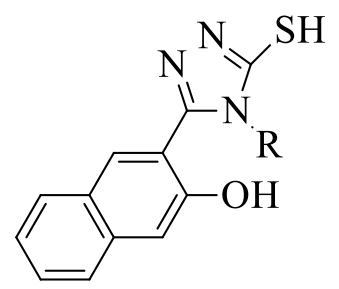

$\mathrm{R}=\mathrm{C}_{2} \mathrm{H}_{5}, \mathrm{CH}_{2}=\mathrm{CHCH}_{2}-, 2-\mathrm{CH}_{3} \mathrm{OC}_{6} \mathrm{H}_{4}, 3-\mathrm{CH}_{3} \mathrm{OC}_{6} \mathrm{H}_{4}$, $4-\mathrm{CH}_{3} \mathrm{OC}_{6} \mathrm{H}_{4}, 4-\mathrm{CH}_{3} \mathrm{CH}_{2} \mathrm{OC}_{6} \mathrm{H}_{4}$

تهدف الدراسة الى تحضير ودراسة عدد من المركبات خماسية الحلقة غير المتجانسة(الثايادايازول والترايازول) نظرا لاهميتها من الناحية الكيميائية من حيث التحضير ودراسة تركييها وتثخيص المركبات المحضرة بالطرق الطيفية المتاحة. الجزء العملي: المواد الكيمياوية والاجهزة المستخدمة: جميع المواد الكيمياوية كانت من انتاج شركتي (FIuka) و(BDH), تم قياس درجات الانصهار للمركبات المحضرة باستخدام Electro thermal IA 9100 melting point Apparatus type (Not corrected) وكانت درجات الانصهار غير مصححة, وتم قياس طيف الاشعة تحت الحمراء لبعض النماذج باستخدام الجهاز : Shimadzu infrared spectrophotometer fourier Transform FTIR-8400S و قياس نماذج اخرى في باستخدام جهاز : Bruker Alpha FTIR, Germany ,Tensor-27

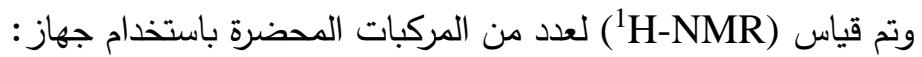
${ }^{1} \mathrm{HNMR}$, Bruker Analytische Messtechnik GmbH,400 MHz وباستخدام (DMSO-d6) بوصفه مذيباً.

\section{Substituted ethyl esters} معوضات استرات الاثيل (2,1)

يضــــاف حامض الكبريتيك المركز (6 مل) الى (0.025 مول) من الحامض الكاربوكســـيلي (2-حامض النفثويك, 4-مثيل حامض البنزويك) المذابة في الايثانول المطلق (15 مل), يصــــد المزيج لمدة (3 ســـاعات), ييرد المزيج, ثم يعادل بمحلول هيدروكسـيد الامونيوم (25\%), يسـتخلص الاســتر باسـتخدام الايثر , يبخر الدذيب ليعطي مادة زيتية من الاسـترين (2,1) على التوالي.اذ اعطى المركب(1) مادة زيتية بنية اللون بدرجة غليان(308-310 م²) وبنسبة ناتج $43 \%$ والمركب (2) مادة زيتية عديمة

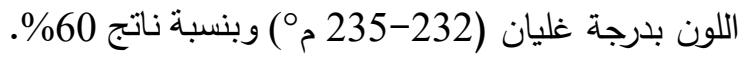

\section{N-(Substituted) hydrazide}

: معوض) هيدرازيد (11,

يصـــد مزيج يحتوي على (2,08 مول) من احد الاسـترين (2,1) و(0.4 مول, 20 مل) من الهيدرازين المائي في (70مل)

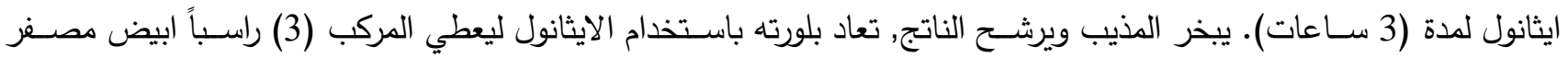


بدرجة انصـهار ( 143-145 مº) وبنسـبة ناتج 72\%, والمركب (4) راسـباً ابيض بلوري بدرجة انصـهار ( 86-87 مº وبنسـبة ناتج . $\% 58$

Substituted thiosemicarbazide

معوضات الثايوسيميكاربازيا (6,5)

من احد الهيدرازيدين (4,3)(0.005 مول) مع ثايوسـيانات الامونيوم (6.005 مول) وحامض الهيدروكلوريك المركز (2 مل) في (50.

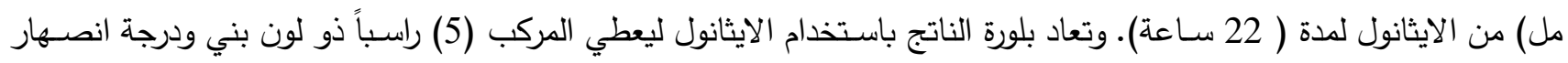

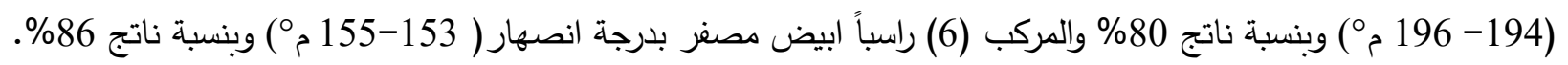

\section{1-(N-Substituted)-4-phenylthiosemicarbazide}

$$
\text { [13](8,7) فعوض(-N)-1 }
$$

يصــد مزيج من (0.001 مول) من احد الهيدرازيدين (4,3) مع (0.001 مول) من فنيل ايزوثايوسـيانات في (50 مل) من

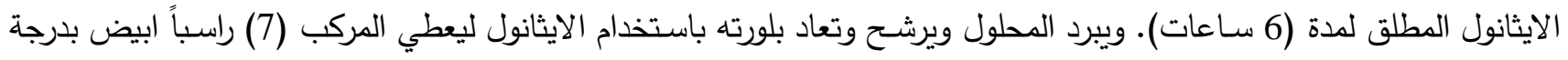

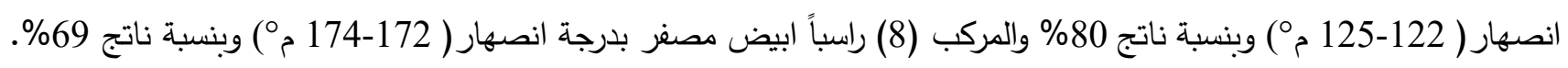

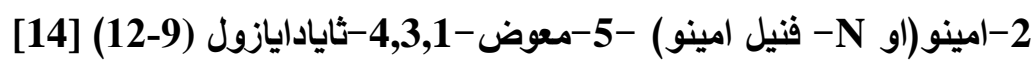

\section{2-Amino(or N-phenylamino)-5-(substituted)-1,3,4- thiadiazole}

[14 [الطريقة الاولىى A

يضــاف (10مل) من حامض الكبريتيك المركز الى (0.002 مول) من احد معوضــات الثايوسـيميكاربازيد (5-8) ثم يحرك

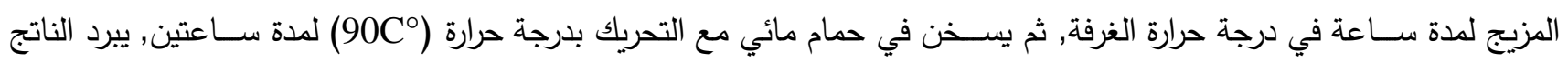
بالثلج ثم يعادل باستخدام هيدروكسيد الامونيوم المركز ويرشـح وتعاد بلورته باستخدام الايثانول.الثوابت الفيزياوية والخواص الطيفية مبينة في الجداول (3,1).

[14] الطريق الثانية

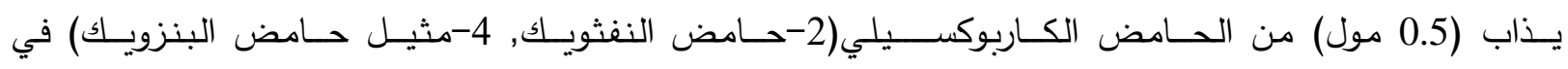
(20 مل) من حامض الكبريتيك المركز مع التبريد والتحريك ثم يضاف (0.5 مول.4.6 غم) من الثايوسيميكاربازيد على شكل دفعات ثم يسـن المحلول في حمام بخاري لمدة (8 سـاعات) ثم يبرد بالثلج. ويعادل باستخدام هيدروكسيد الامونيوم ويرشـح, وتعاد بلورته باستخدام الايثانول. 
الجدول(1): بعض الثوابت الفيزياوية لمركبات 2-امينو (او N- فنيل امينو) -5-معوض - 4,3,1-ثايادايازول(12-9)

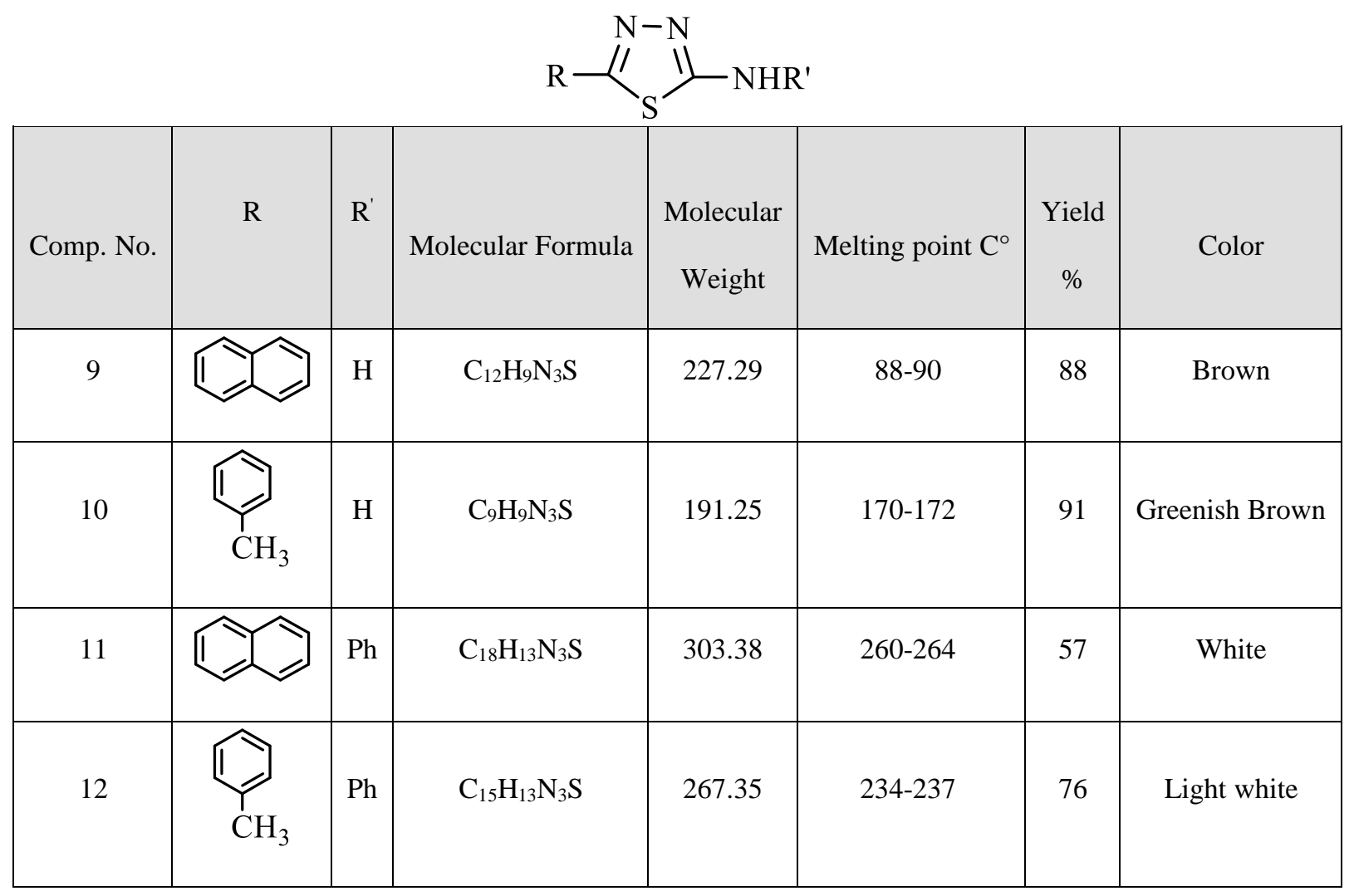

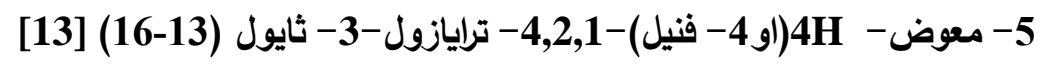

\section{5-Substituted-4H(or4-phenyl)-1,2,4-triazole-3-thiol}

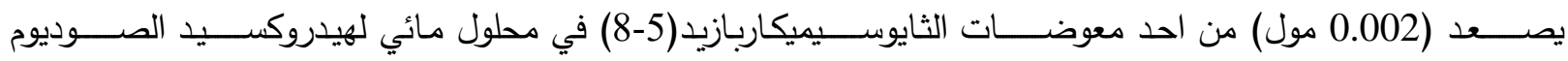

(25 مل, 4\%) مدة (3 سـاعات). ويعامل المحلول الناتج مع الفحم المنشـط ويرشـح ترشـيحاً سـاخناً ثم يحمض باستخدام (10\%)

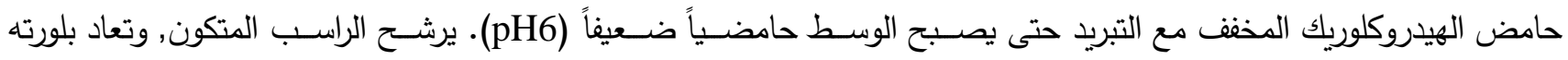
باستخدام الايثانول والماء. ان الثوابت الفيزياوية والخواص الطيفية مبينة في الجداول(4,2). 
الجدول (2): بعض الثوابت الفيزياوية لمركبات 5 -معوض -4H(او4-فنيل)-4,2,1-ترايازول-3-ثايول (16-13)



[7]

\section{3,4-Diamine-5-substituted-4H-1,2,4-triazole}

يمزج (0.005 مول) من مشتق الثايوسيميكاربازيد (6,5) مع (0.2 مول, 10 مل) من الهيدرازين المائي ثم يصعد المزيج لمدة

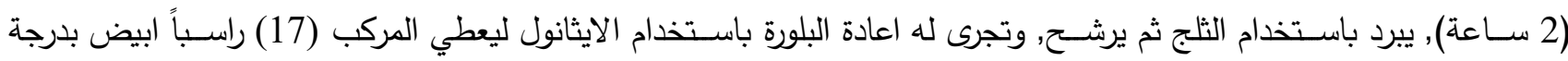

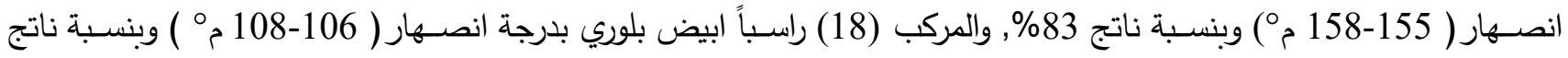

مول) من احد معوضات الهيدرازيدين (4,3) مع (50 مل) من رباعي هيدروفيوران الجاف ويضاف ببطء مع التحريك والتبريد (10.01 (15)

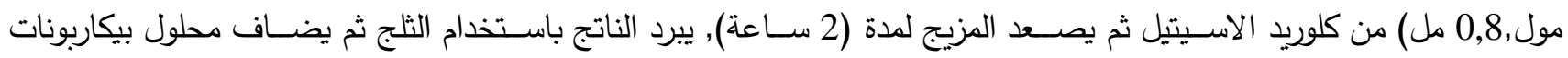

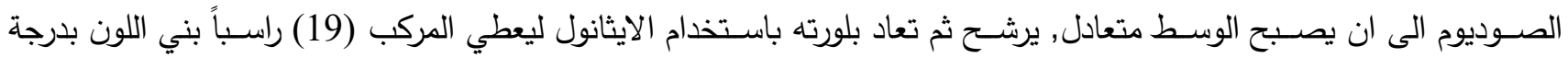

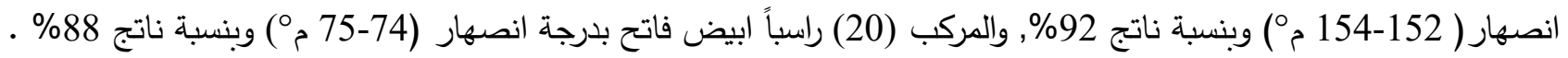


20 2-Methyl-5-substituted-1,3,4-thiadiazole

يصــــد مزيج مكون من (0.025 مول) من احد المركبات (20,19) و(0.05 مول,1.1غم) من خماســي كبريتيد ثنائي الفسفوفي (100 مل) من الزايلين لمدة (1 سـاعة). يبخر الدذيب وتعاد بلورة الناتج باسـتخدام الايثانول ليعطي المركب (21) راسباً

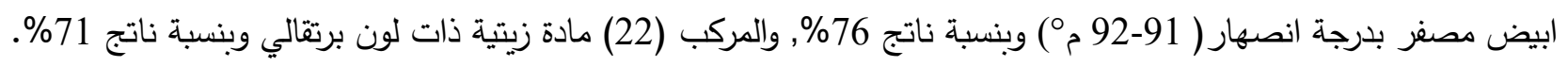

\section{: Result \& Discussion النتائج والمناقثة}

تم في هذا البحث تحضير الاسترين (2,1) من مفاعلة الحامض الكاربوكسيلي (2-حامض النفتويك, 4-مثيل حامض البنزويك) مع حامض الكبريتيك المركز في الايثانول المطلق [10]. وشخص المركبين الناتجين طيفياً باستخدام طيف الاشعة تحت الحمراء اذ اعطى طيف المركبين(1) و (2) حزمة مندة مط الاصرة منفردة عند C-O عند C=O مجموعة (O-H) التي كانت تعود للحامض الكاربوكســيلي وارتفاع قيمة مط مجموعة الكاربونيل في الاســتر مقارنة مع قيمتها في

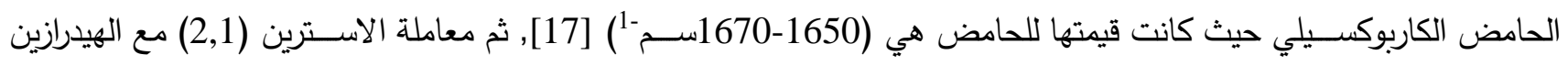
المائي في الايثانول ليعطي مركبي N- معوض هيدرازيد (4,3) كما موضح في الميكانيكية التالية [18]:

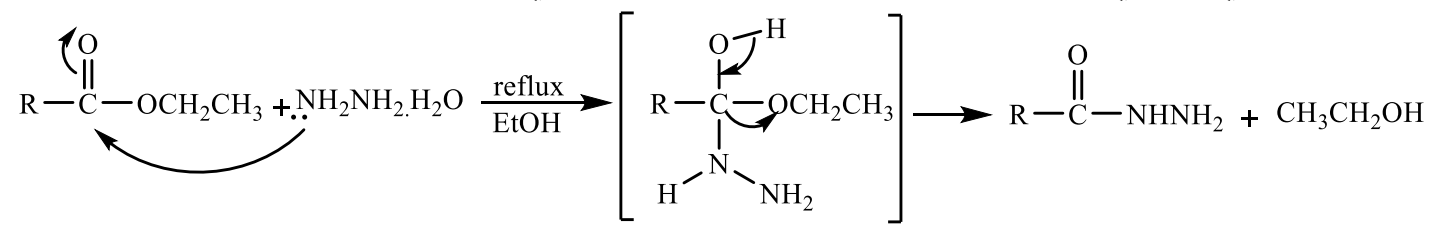

وتم تثـخيص مركبي الهيدرازيد المحضـرة بواسـطة طيف الاشـعة تحت الحمراء, اذ اعطى طيف المركبين(3) و (4) حزمتين

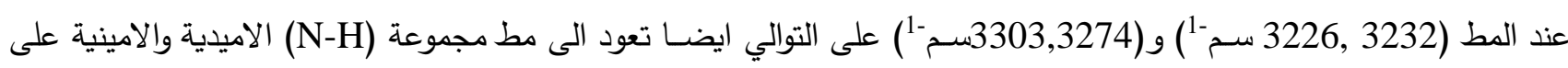
التوالي. كما لوحظ ان مجموعة الكاربونيل تعطي امتصاصات اوطا مما هي عليه في الاستر , اذ اعطى المركبين (3) و (4) حزماً عند (1660,1600)

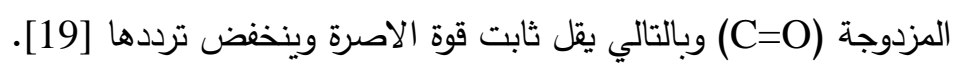

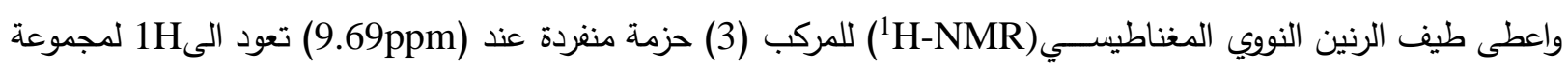

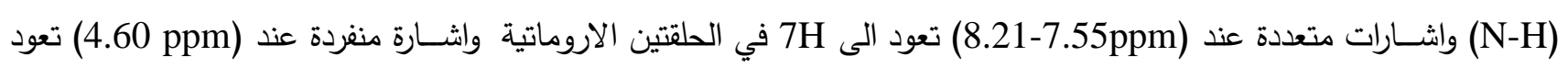
الى $2 \mathrm{H}$ لمجموعة (17) وقد حضـــرت مركبات الثايوســيميكاربازيد (6,5) من تفاعل الهيدرازيد (4,3) مع ثايوســـــانات الامونيوم بوجود حامض الهيدروكلوريك المركز . اما مركبات 1-N) - معوض)-4- فنيل ثايوسيمكاربازيد (8,7) فقد حضرت بمفاعلة الهيدرازيد (4,3) مع ايزوثايوسيانات الفنيل في الايثانول. وتكمن اهمية هذه المركبات بامكانية تحويلها الى الثايادايازول في الوسط الحامضي والى الترايازول في الوسط القاعدي[12].

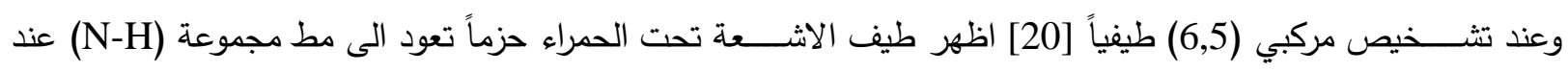

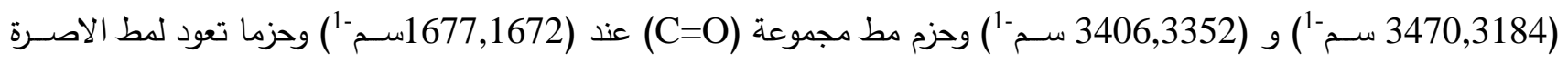
عند (C=S) 


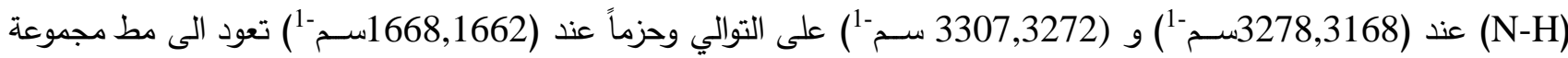

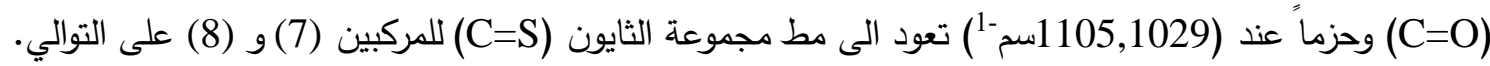

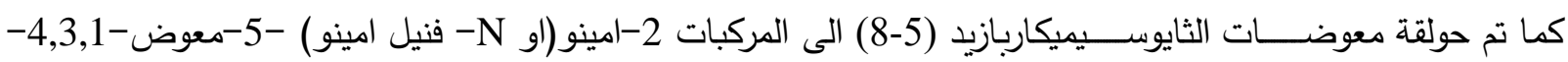
ثايادايازول (12-9) بمفاعلتها مع حامض الكبريتيك المركز [14]. اذ لوحظ في طيف الاثـــعة تحت الحمراء اختفاء امتصــــاص المط لمجموعة الكاربونيل وظهور حزمة عند التردد (-1662 1610سم-10) تعود الى مط المجموعة (C=N) فضـلا عن حزمة مط المجموعة (N-H) في المدى (3217-376 سمَ'), و حزمة المط للمجموعة (1058-1027سم-1), لوحظ ان هذه القيم تتقق مع ماذكر في الادبيات [21) (21).

الجدول (3) يبين الخواص الطيفية لمركبات 2-امينو (او N- فنيل امينو)-5-معوض - 4,3,1-ثايادايازول

\begin{tabular}{|c|c|c|c|c|c|c|c|}
\hline \multirow{2}{*}{ Comp. No. } & \multirow{2}{*}{$\mathrm{R}$} & \multirow{2}{*}{$\mathrm{R}^{\prime}$} & \multicolumn{5}{|c|}{ IR v cm ${ }^{-1}(\mathrm{KBr})$} \\
\hline & & & $\mathrm{N}-\mathrm{H}$ & C-H Ar & C-H Alph & $\mathrm{C}=\mathrm{N}$ & C-S-C \\
\hline 9 & & $\mathrm{H}$ & 3376 & 3032 & --- & 1662 & 1027 \\
\hline 10 & $\mathrm{CH}$ & $\mathrm{H}$ & 3284 & 3093 & 2958 & 1631 & 1058 \\
\hline 11 & & $\mathrm{Ph}$ & 3300 & 3008 & ---- & 1610 & 1046 \\
\hline 12 & $\mathrm{CH}$ & $\mathrm{Ph}$ & 3217 & 3035 & 2877 & 1650 & 1035 \\
\hline
\end{tabular}

وحضرت مركبات 5- معوض - 4H(او4- فنيل)-4,2,1- ترايازول-3- ثايول (13-16) من التصعيد الحراري لمشتق الثايوسيميكاربازيد (5-8) في الوسط القاعدي المخفف[13]. وتم تثــيص مركبات الترايازول المعوضـــة بالطرائق الطيفية, تميز الطيف باختفاء الحزمة العائدة لمجموعة الكاربونيل التي

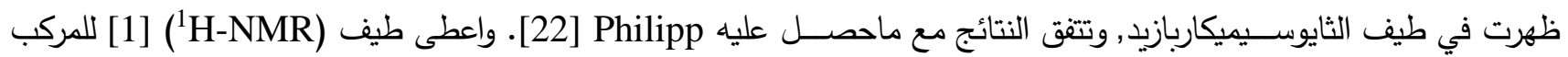

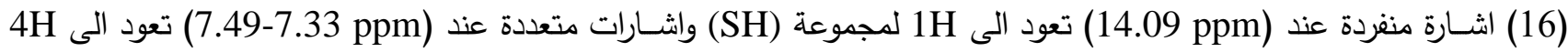
للحلقة الاروماتية (Ar-CH3 (2.26 ppm) 
الجدول (4): يبين الخواص الطيفية لمركبات 5-معوض-4H(اوفنيل)-4,2,1-ترايازول-3-ثايول<smiles>[R]c1nnc(S)n1[R]</smiles>

\begin{tabular}{|c|c|c|c|c|c|c|c|}
\hline \multirow{2}{*}{ Comp. No. } & \multirow{2}{*}{$\mathrm{R}$} & \multirow{2}{*}{$\mathrm{R}^{\prime}$} & \multicolumn{5}{|c|}{ IR v cm ${ }^{-1}(\mathrm{KBr})$} \\
\hline & & & $\mathrm{N}-\mathrm{H}$ & C-H Ar & C-H Alph & $\mathrm{C}=\mathrm{N}$ & $\mathrm{C}=\mathrm{S}$ \\
\hline 13 & & $\mathrm{H}$ & 3487 & 3049 & ---- & 1676 & 1143 \\
\hline 14 & & $\mathrm{H}$ & 3446 & 3072 & 2977 & 1679 & 1118 \\
\hline 15 & & $\mathrm{Ph}$ & 3280 & 3076 & ---- & 1620 & 1168 \\
\hline 16 & $\mathrm{CH}_{3}$ & $\mathrm{Ph}$ & 3303 & 3082 & 2918 & 1662 & 1116 \\
\hline
\end{tabular}

وحضر مركبي 4,3- ثنائي امين- 5- معوض-4H-4,2,1-ترايازول (18,17) من تصعيد احد معوضات الثايوسيميكاربازيد (6,5) مع الهيدرازين المائي لمدة ساعتين, كما موضح في الميكانيكية التالية [7]:

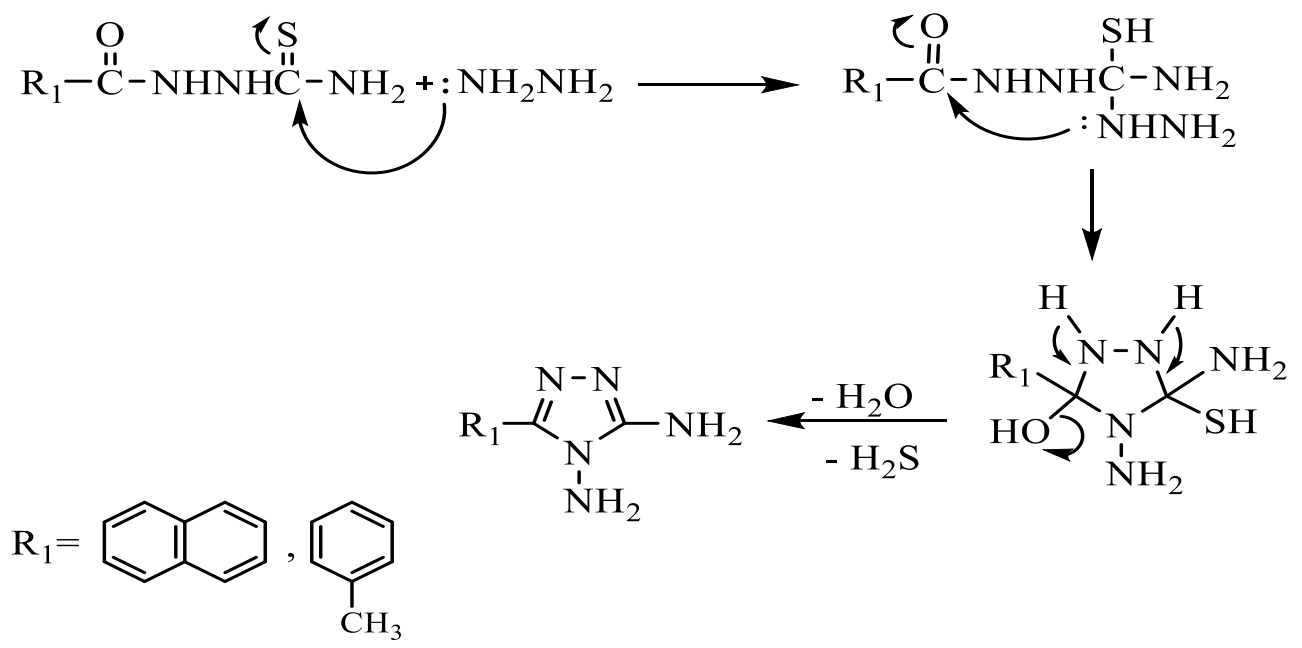

وتم تشخيص المركبين المحضرين طيفياً باستخدام طيف الاشعة تحت الحمراء (IR) اذ اظهر المركبين (17) و(18) حزمة

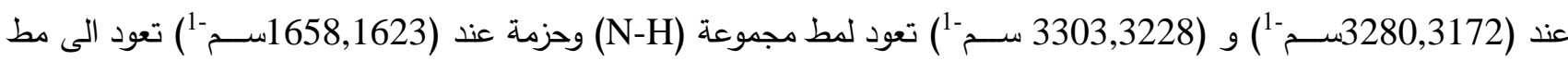
الاصـــرة (C=N) للمركبين على التوالي. تميز الطيف باختفاء الحزم العائدة لمط مجموعة الكاربونيل والثايون التي ظهرت في طيف وحته

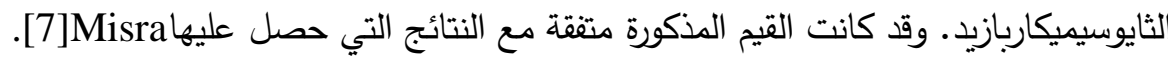


كما تم مفاعلة مركبات الهيدرازيد(4,3) مع كلوريد الاســـيتيل للحصــــل على المركبين N-اســـيتيل -N-معوض هيدرازين

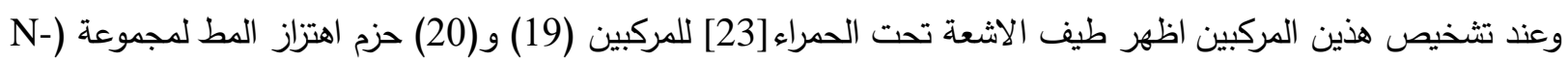

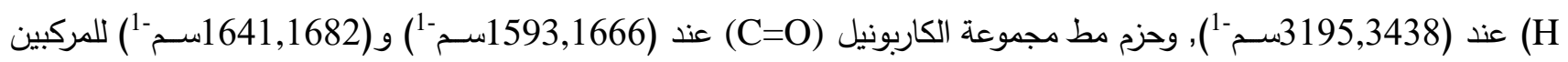

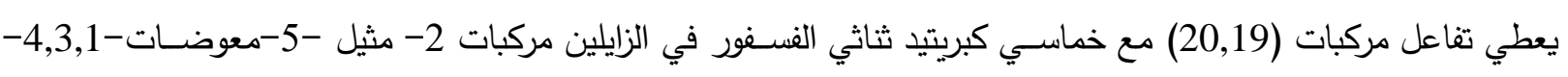
على التوالي.

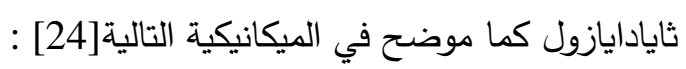

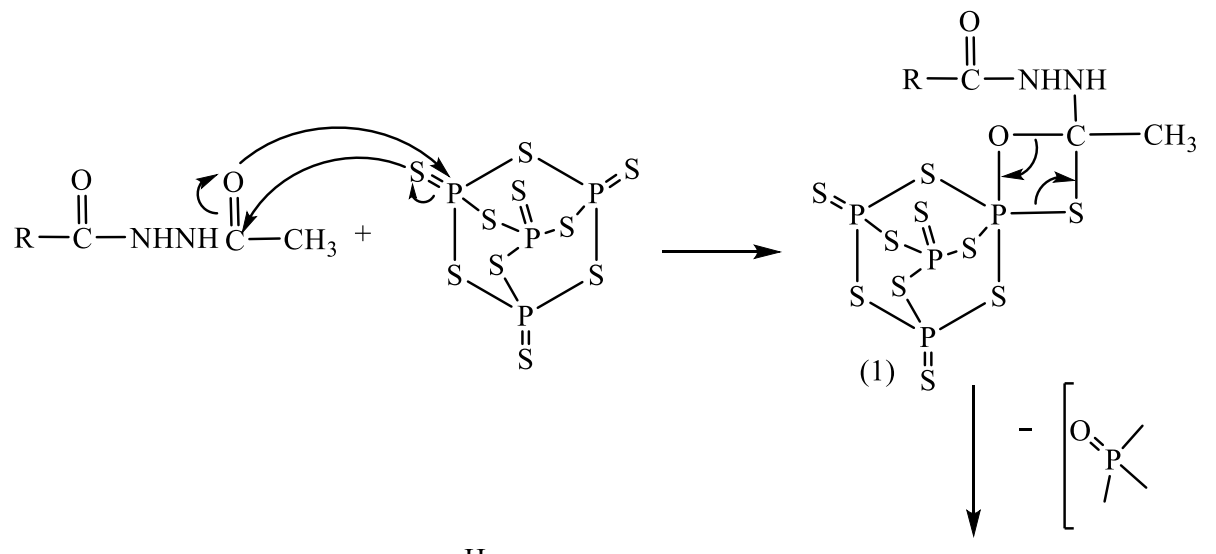<smiles>[R]c1nnc(CC2CC2)s1</smiles><smiles>[R]C1(O)NN2N=C(C)SC21</smiles>

(3)<smiles>[R]C(=O)NN1NCC(C)(C)CS1</smiles>

(2)

$\mathrm{R}=$<smiles>Cc1ccccc1-c1ccc2ccccc2c1</smiles>

وعند تثـخيص هذين المركبين طيفياً , اذ اظهر طيف الاثـعة تحت الحمراء[25] للمركبين (21) و(22) حزمة مط مجموعة (C-S-C) عند (C=N) لمط مجموعة الكاربونيل في مركبات N- اسيتيل -N- معوض الهيدرازيد.

تم بنجاح في هذا البحث تحضـير مركبات جديدة من 4,3,1- ثايادايازول(9-12 و 22,21) و 4,2,1- ترايازول(13-18) من

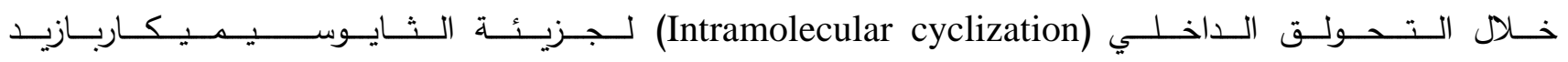
(5-8), وتم تثخيص المركبات طيفياً. نأمل ان يتم اضافة الدراسة البايولوجية في المستقبل. ويعتبر هذا البحث بمثابة دعم التخطيط لجزيئات جديدة تحتوي على هذه المركبات ومن مراجعة الادبيات ان هذه المركبات تحتوي على النظام الحلقي غير المتجانس والتي لها تطبيقات طبية واسعة. 

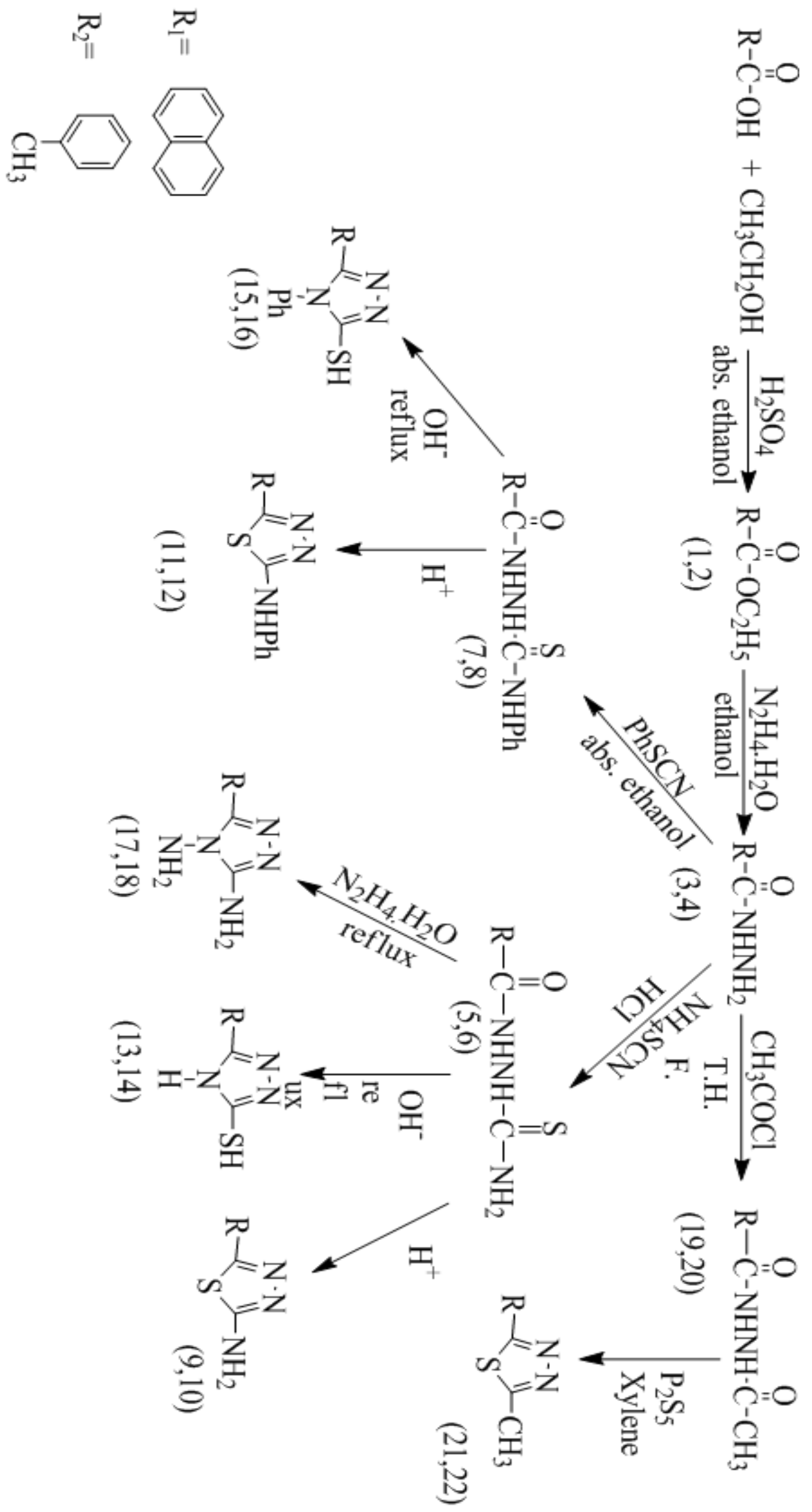
Journal of Education and Science (ISSN 1812-125X), Vol: 29, No: 1, 2020 (43-59)

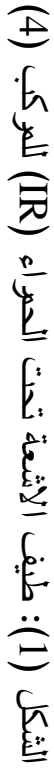

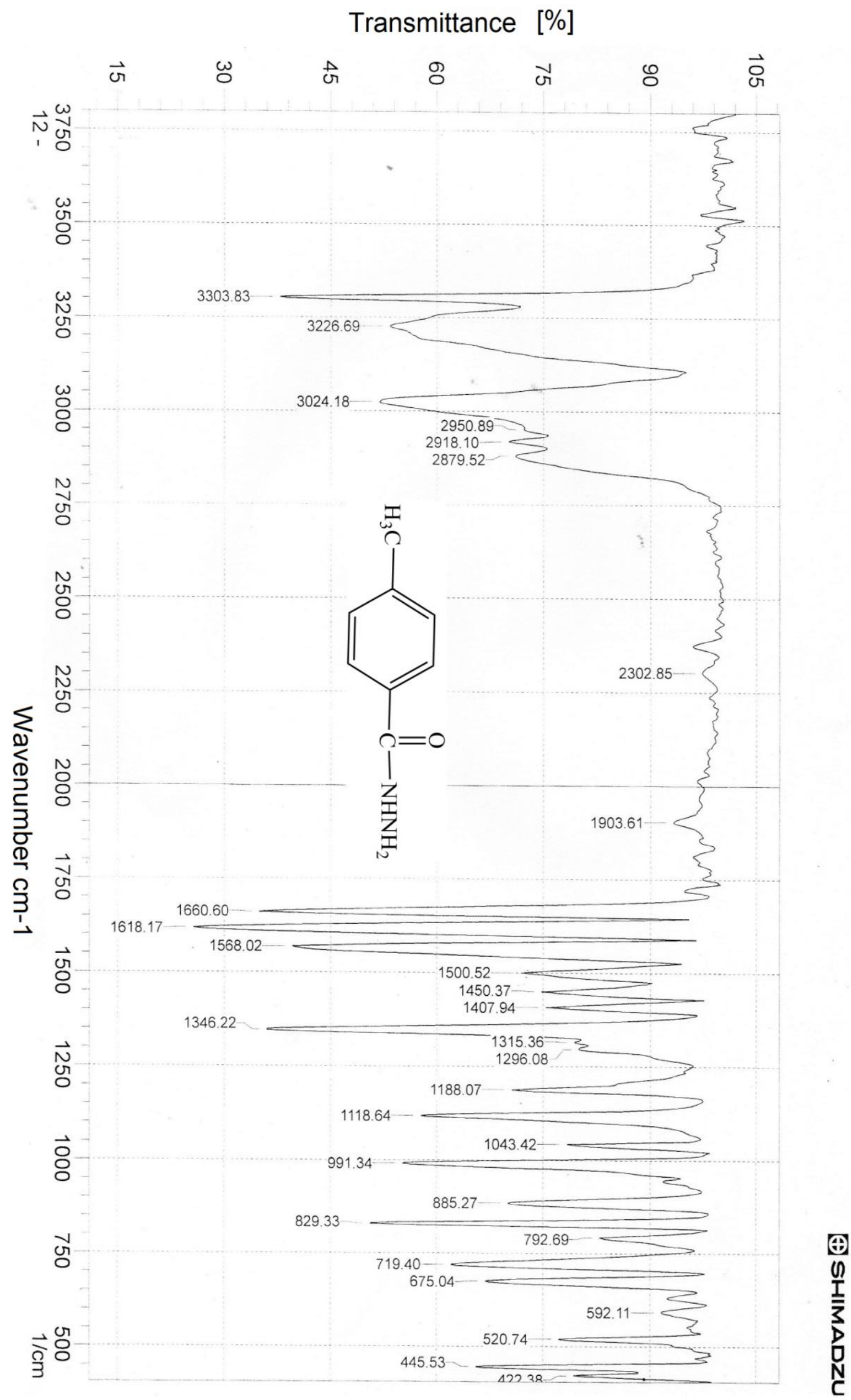




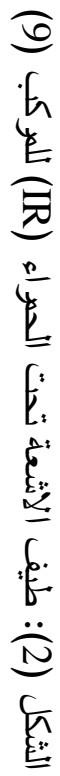

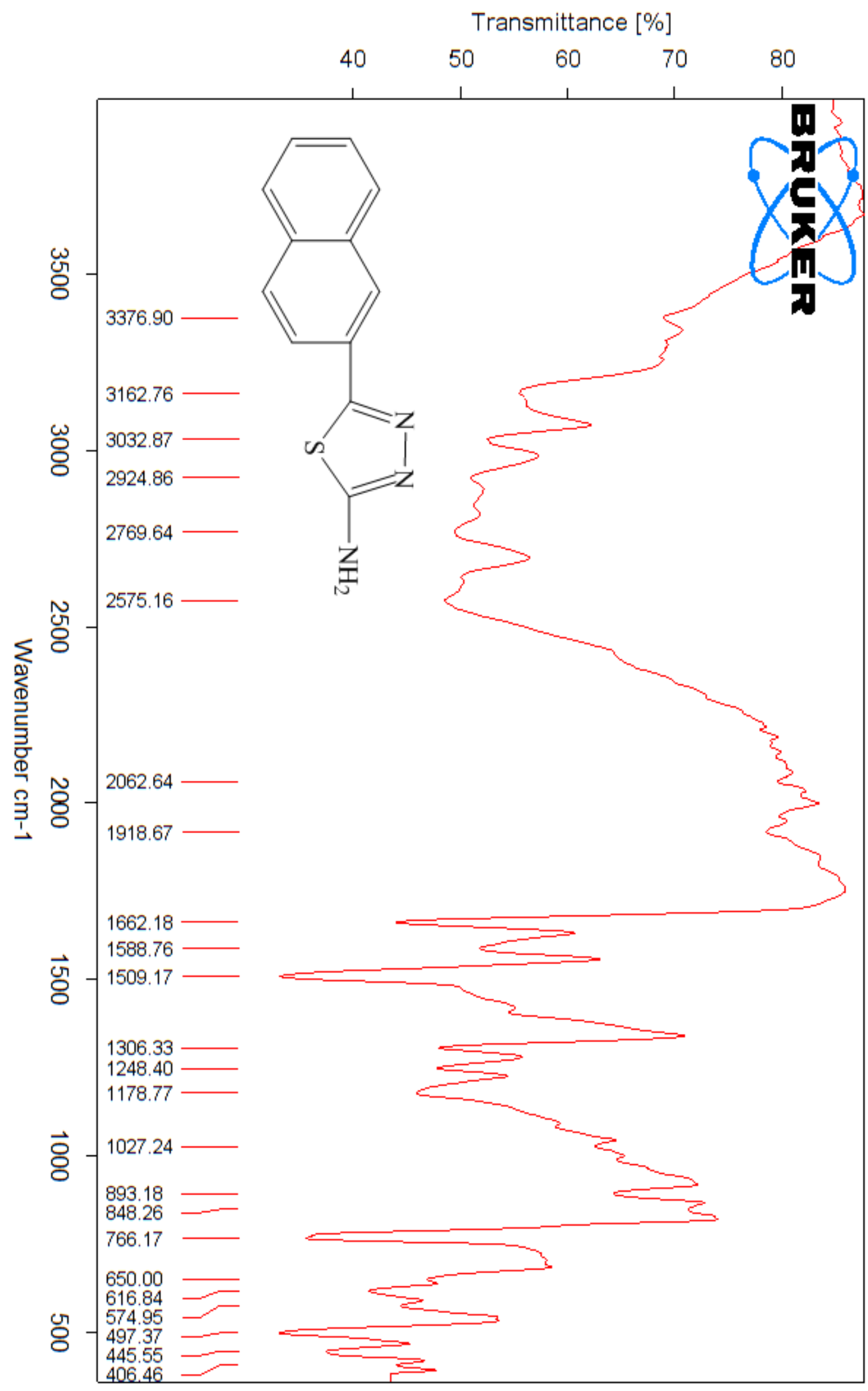




\section{Transmittanse [\%]}

$\circ$ जे के $\varnothing$ जै $\varnothing$ के

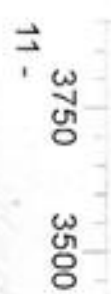

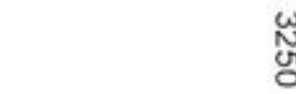

$\underset{\text { W }}{\text { W }}$

\%
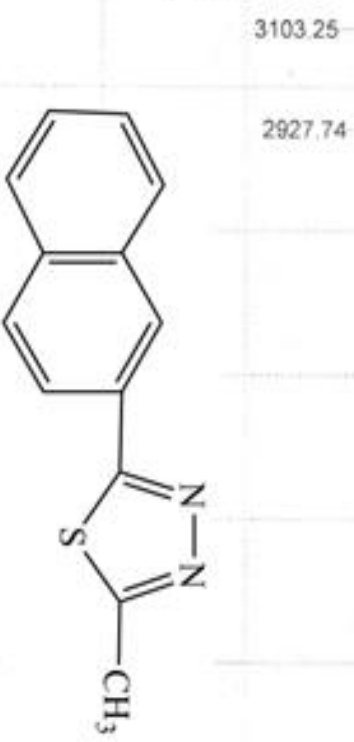

กั้
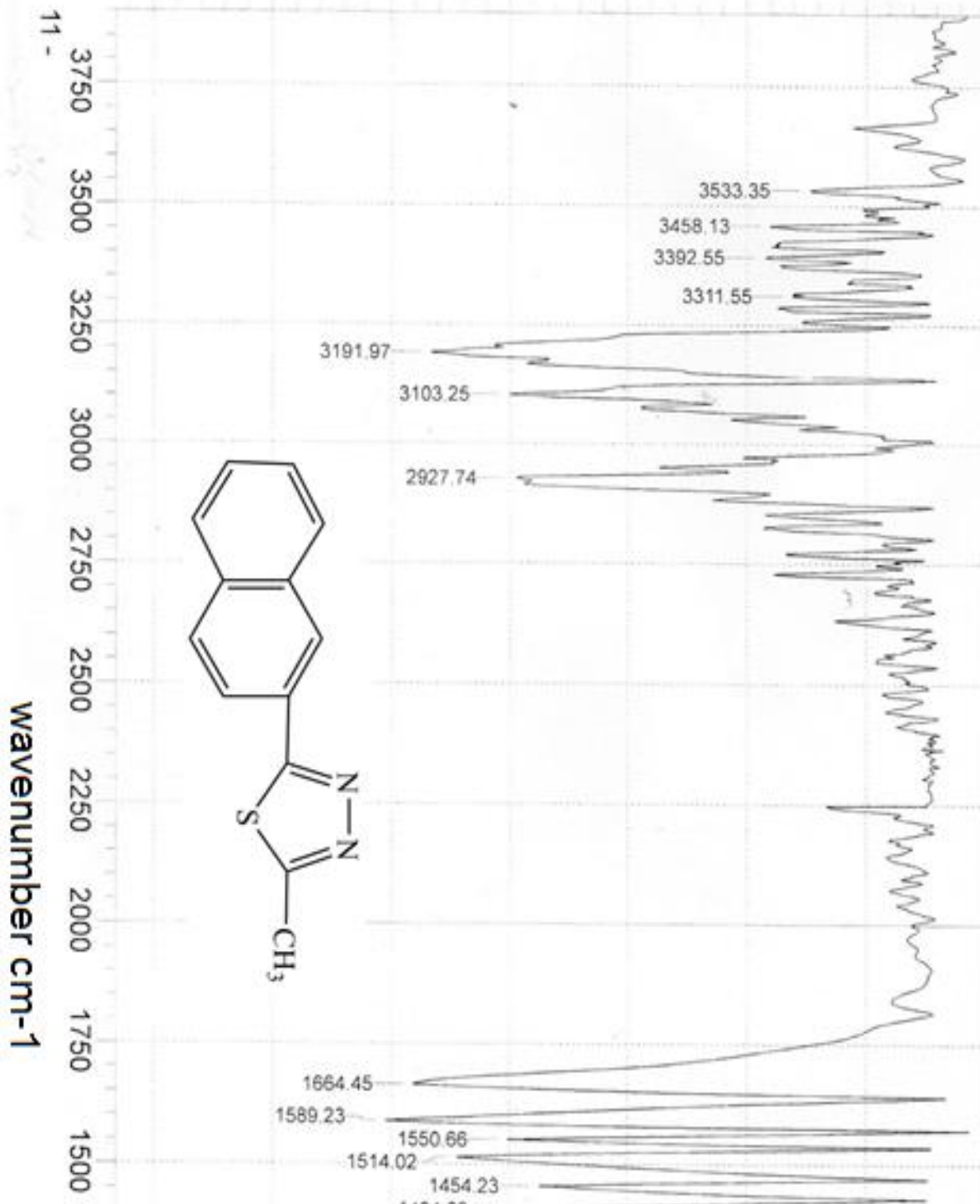

ఝั
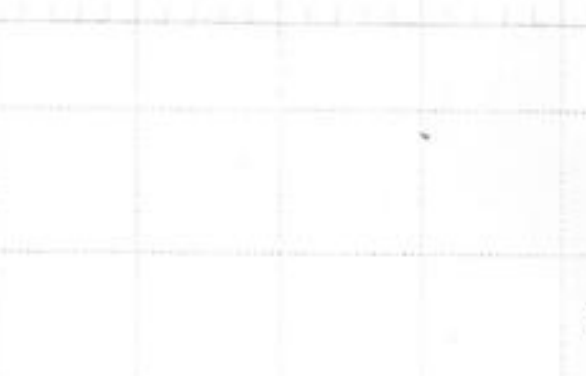


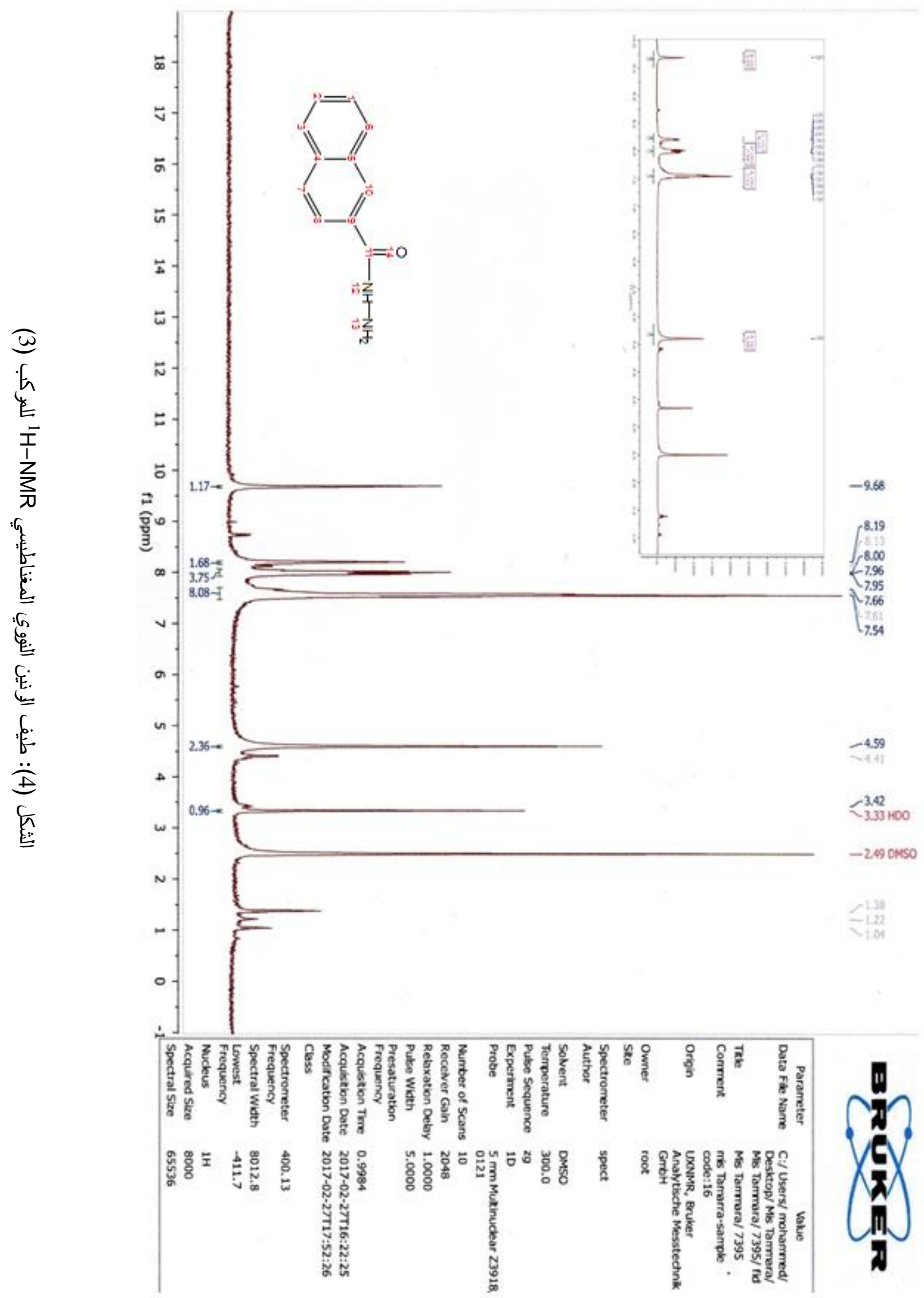




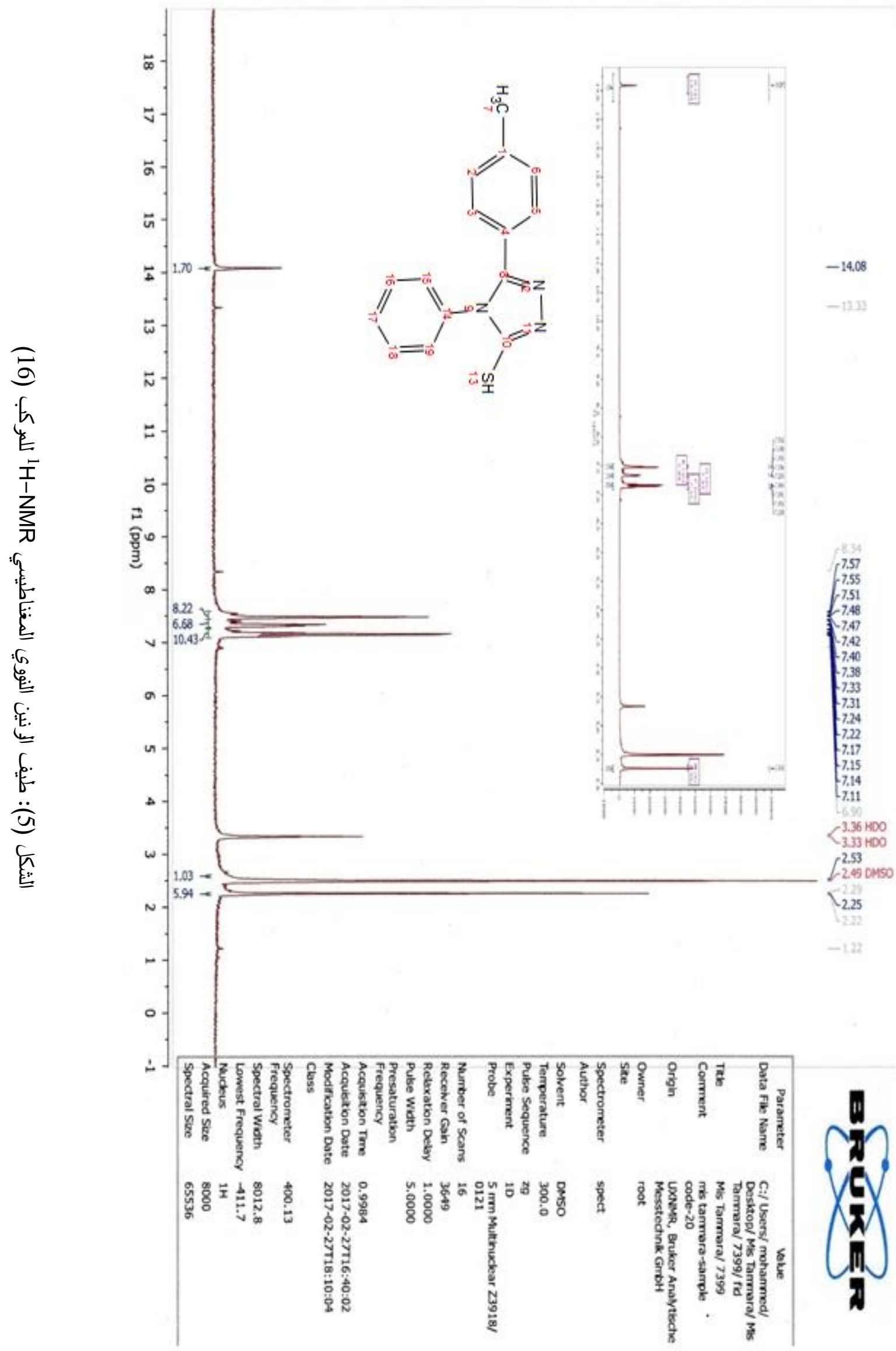




\section{المصادر References:}

1. Reddy Ch. S., Devi M. V., Sunitha M. and Nagaraj A., Indian J. Chem., 55B: 590-597 (2016).

2. Rad O., Tibor R., Duma M. and Vlase L., Studia. Ubb. Chemia., Lxi, 1: 17-32 (2016).

3. Abdelriheem N. A., Mohamed A. M. and Abdelhamid A.O, Molecules., 22: 268 (2017).

4. Kataritzky A. R. and Rees C.W, Pergamon Press Ltd., England, 6: 427 (1984).

5. Petrow V., Stephenson O., Thomas A. J. and Wild A. M.,

J. Chem. Soc., Part2: 1508 (1958).

6. Radwan A. A., Alanazi F. K. and Al-Agamy M. H., Braz. J. Pharm. Sci., 53:e15239 (2017).

7. Misra U., Hitkari A., Saxena A. and Shanker K., Eur. J. Med. Chem., 31: 629-634 (1996).

8. Katica C. R. , Vesna D., Vlado K. and Aleksandra B., Molecules., 6: 815-824 (2001).

9. Popiolek L., Paruch K., Patrejko P. and Biernasiuk A, J. Iran Chem. Soc., 13: 1945-1951 (2016).

10. Sakis G. Y. and Matti F. S., Iraq J. Chem., 16:52 (1991).

11. Yale H. L., Losee K., Martins J. and Bernstein J., J. Am. Chem. Soc., 75:1933 (1953).

12. Wu M. T., J. Heterocyclic Chem., 9:31 (1972).

13. El-Khawass S. M. and Habib N. S., J. Heterocyclic Chem., 26:177 (1989).

14. Farghaly A. and El-Kashef H., ARKIVOC., (xi): 7690 (2006).

15. Shafiee A., Yazdikarimy B. and Sadrai S., J. Heterocyclic Chem., 26:1341 (1989).

16. Goswami B. N., Kataky J. C. S. and Baruah J. N., J.Heterocyclic Chem., 21:1225 (1984).

17. Wade L. G. and Simek J. W., “Organic Chemistry”. $9^{\text {th }}$ ed. New York. London. Inc. (2016).

18. March J., "Advanced Organic Chemistry;Reactions, Mechanisms and Structure”. $7^{\text {th }}$ ed. McGrowHill Co., Japan, p.307 (2013).

19. Silverstein R. M., Bassler G. C. and Morrill T. C., "Spectrometric Identification of Organic Compounds". $3^{\text {th }}$ ed. John Wiley \& Sons Inc.New York (1974).

20. Zamani K., Faghihi K., Sangi M. R. and Zolghavnein J., Turk. J. Chem., 27:119-125. (2003).

21. Daoud K. M. and Ahmad A. K., J. Edn. Sci., 41:22 (2000).

22. Erno B. P., Philippe B. and Martin B., "Structure Determination of Organic Compound Tables of Spectral Data”. Verlag Berlin Heidelberg. (2009).

23. Williams D. H. and Fleming I., "Spectroscopic Methods in Organic Chemisty". $7^{\text {th }}$ ed. Springer International Publishing,Switzerland AG (2019).

24. Barkovic I.D. and Morvin M., Acta Pharm. Jugoslov, 11, 39:Chem. Abst.,57:1-3, 2338h (1962).

25. Field L.D., Strenhell S. and Kalman J., “Organic Structuers From Spectra”. $5^{\text {th }}$ ed. John Wiely \& Sons, Ltd (2012). 